\title{
Numerical Modeling of Fluid Flow and Heat Transfer Through Helical Tube
}

\author{
Satish K. Dewangan*, Dedavath K. Kumar \\ Mechanical Engineering Department, National Institute of Technology Raipur (CG), Raipur 492010, India
}

Corresponding Author Email: skdewangan.mech@ nitrr.ac.in

https://doi.org/10.18280/ijht.380232

Received: 15 June 2019

Accepted: 4 March 2020

\section{Keywords:}

food preservation, food processing, helical tube heating, microwave heating, CFD

\begin{abstract}
This study is focused on the numerical investigation of fluid flow and heat transfer in a helical tube of continuous flow microwave heating. A numerical model is developed to predict the flow distribution, skin friction coefficient, pressure drop and heat flux of liquid food products (Newtonian as well as non-Newtonian products) heated in the helical tube using ANSYS software. The simulated temperature distribution and energy distribution are verified with experimental studies published in the literature. Comparison of the simulated temperature distribution with the experimental data for Distilled water, CMC-0.5\%, and CMC-1\% are in good agreement. Mesh refinement is studied. Fluid flow simulation has been performed for different fluids (Apple sauce, Tomato sauce, Skim milk, Distilled water, CMC- $0.5 \%$, and CMC- $1 \%$ solutions) at different flow rates $(1,2,3,4$ and $5 \mathrm{~L} / \mathrm{min})$ in helical tubes with pitch lengths $0.124 \mathrm{~m}, 0.062 \mathrm{~m}$ and $0.186 \mathrm{~m}$ respectively. The skin friction coefficient and pressure drop of the fluids across the three tubes at the mentioned flow rates are obtained and compared graphically. Heat flux required by Apple sauce, Tomato sauce, and Skim milk to attain $60^{\circ} \mathrm{C}$ at the outlet is obtained. The viscous model used for the simulation is the laminar model.
\end{abstract}

\section{INTRODUCTION}

Pasteurization/sterilization of fluid food products can be carried out either by canning or aseptic processing. Although canning is the dominant technology used by the food industry, it is known to result in widespread damage to quality and nutrients in highly viscous products due to the slow rate of heat transfer. Aseptic processing (continuous-flow heating) has the potential to improve product quality and reduce nutrient losses by allowing for heating rapidly and uniformly in comparison to canning. However, despite these advantages, non-uniform heating of highly viscous fluid foods in conventional aseptic processing systems (heat exchangers) remains a problem. Microwave volumetric heating may eliminate this drawback of conventional heat exchangers.

The heat transfer and temperature distribution analysis in the continuous microwave system has been the area of interest for many researchers across the world. Earlier research has showed that uniform temperature distribution by continuous microwave system can be achieved for low viscous fluid products such as apple juice: Gentry and Roberts [1], orange juice: Nikdel [2] and milk: Coronel [3], Sierra [4], Valero [5] and Villamiel [6]. Non-uniform temperature distribution in a continuous-flow microwave system was reported for sweet potato puree: Coronel [7] and Steed [8], green pea/carrot puree: Kumar [9]. Thostenson [10] studied microwave processing in a very detailed manner which is a relatively new development in materials processing. Coronel [3] designed a continuous-flow microwave applicator to heat milk with different fat contents at various flow rates. Temperature profiles at the exit of the applicator were measured. Gentry and Roberts [1] concluded that by the physical design of the system, volume capacity and volumetric flow rates, the application of microwave energy for the pasteurization of apple cider is a feasible thermal process, especially with increased power. Zhu [11] developed a numerical model for simulating forced convection of a liquid continuously flowing in a circular applicator that is subjected to microwave heating. Coronel [9] measured dielectric properties of solutions of table salt, sugar, $\mathrm{CMC}$, and mixtures of these solutes and correlations for the dependence of dielectric properties on the concentration of solute and temperature were developed. Salvi [12] studied the effect of different dielectric properties and flow rate on heating patterns of tap water, saltwater and CMC in a continuous flow microwave system by employing a single fiber optic probe. Romano and Apicella [13] formulated a mathematical model to describe the heat transfer in liquid foods flowing in circular ducts, subjected to microwave irradiations. Tuta [14] designed a continuous flow microwave system for uniform heating of high-viscosity fluid food products (Distilled water, CMC-0.5\%, and CMC- $1 \%$ solutions) was numerically modeled and the model was experimentally validated. Tang et al. [15] carried out numerical simulation for exploring velocity distribution, pressure field, and secondary flow in a helical tube by varying coil parameters such as coil pitch, curvature radius and Dean Number. Kalla [16] provided a brief update of microwave heating with special emphasis on food quality in terms of microbial and nutritional value changes. Jain [17] studied the performance of metal carriers for food packages in the microwave assisted thermal pasteurization system. Jain [18] developed a mathematical model for predicting electromagnetic power dissipation within a rectangular dielectric slab. 


\section{PROBLEM FORMULATION MATHEMATICAL MODELLING}

AND

This section contains the summary of the problem concluded based on the need of the application undertaken and based on its other recent researches. Further the physical aspects of the investigations (i.e. continuous helical tube flow microwave heating) like configuration of the helical flow domain, properties of different types of the fruit/kitchen juices, kinematic parameters taken, the aspects of the investigations have been discussed. Based on the nature of the flow, the relevant mathematical modeling has been briefed also.

\subsection{Physical aspects of investigation}

Most of the authors have done the analysis of thermal distribution in fluids like apple juice, orange juice, milk, sweet potato puree, green pea/carrot puree. Straight applicator tube has been used as the treatment chamber in most cases. Tuta [14] used a curved tube i.e., helical tube for experimental investigation on distilled water, CMC- $0.5 \%$, and CMC- $1 \%$ solutions. The flow characteristics of the helical tube are also an important area to study. Till date, very few researchers have presented the effect of flow characteristics and heat transfer through the helical tube for the fluid food products Apple sauce, Tomato sauce and Skim milk, Distilled water, CMC$0.5 \%$, and CMC- $1 \%$. In the present study, steady-state flow characteristics and heat transfer through helical tubes were studied numerically. Simulations were conducted with the fluids at flow rates of $1,2,3,4$ and $5 \mathrm{~L} / \mathrm{min}$. The numerical model was developed in ANSYS software and model validation was carried out by comparing simulation results with Tuta [14] experimental results.

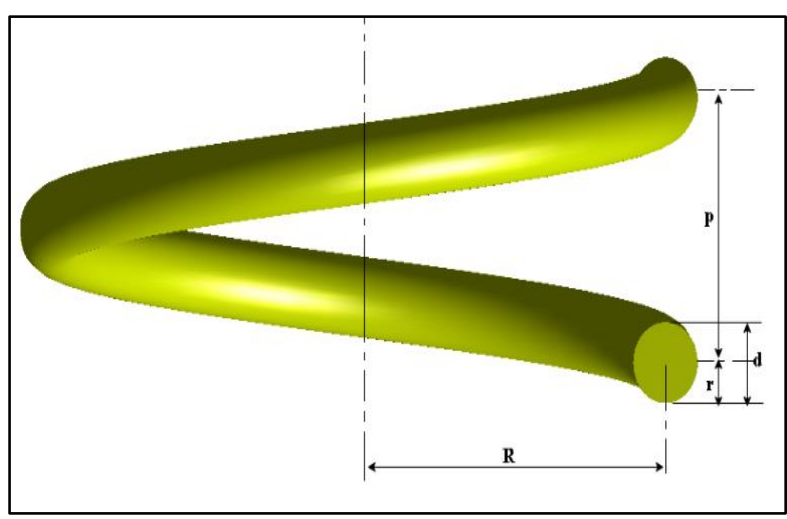

Figure 1. The geometry of the helical fluid domain

For the purpose of thermal and flow characteristics investigation of continuous flow microwave heating within the helical heating tube (taken inside the microwave enclosure) the dimensional details of helical tube clubbed with the intake $\&$ exit straight tube is given in Table 1 . Figure 1 is showing the geometry of the helical fluid domain. In Figure 1, the notations $p, R$ and $d$ are pitch length (m), the radius of the helical coil $(\mathrm{m})$, and the diameter of the helical tube $(\mathrm{m})$ respectively. For three different pitches of the helical tube, three different helical tubes have been modeled with pitches $0.124,0.062$ and $0.186 \mathrm{~m}$. The list of the various simulation cases has been briefed in Table 2. Thermophysical properties of the different fluid juices taken for simulation are given in Table 3 .

Table 1. Helical and straight tube dimensional formulations of all the three tubes

\begin{tabular}{|c|c|c|c|c|}
\hline Helical tube topology & Tube 1 & Tube 2 & Tube 3 & Relevant expression used \\
\hline Helical dia, $D(\mathrm{~m})$ & 0.0362 & 0.0362 & 0.0362 & $2 R$ \\
\hline Coil perimeter, $C(\mathrm{~m})$ & 0.11373 & 0.11373 & 0.11373 & $\pi D$ \\
\hline Pitch length, $p(\mathrm{~m})$ & 0.124 & 0.062 & 0.186 & Given \\
\hline Helical length, $h_{L}(\mathrm{~m})$ & 1.144 & 1.139 & 1.1524 & $\sqrt{p^{2}+C^{2}}$ \\
\hline Total length, $L(\mathrm{~m})$ & 1.54 & 1.54 & 1.54 & Given \\
\hline Remaining length, $L_{r}(\mathrm{~m})$ & 0.396 & 0.401 & 0.3876 & $L-h_{L}$ \\
\hline Straight tube length on both ends, $L_{s}(\mathrm{~m})$ & 0.198 & 0.2005 & 0.1938 & $\frac{L_{r}}{2}$ \\
\hline Mean diameter, $d(\mathrm{~m})$ & 0.038 & 0.038 & 0.038 & $2 r$ \\
\hline Cross sectional area, $a\left(\mathrm{~m}^{2}\right)$ & 0.001134 & 0.001134 & 0.001134 & $\pi r^{2}$ \\
\hline Wall surface area, $A\left(\mathrm{~m}^{2}\right)$ & 0.18385 & 0.18385 & 0.18385 & $\pi d L$ \\
\hline
\end{tabular}

Table 2. The list of various simulations undertaken

\begin{tabular}{ccccc}
\hline S.N. & Fluid type & Tube topology & $\mathbf{Q}(\mathbf{L} / \mathbf{m i n})$ & $\mathbf{V}=\mathbf{Q}^{*} / \mathbf{a}(\mathbf{c m} / \mathbf{s})$ \\
\hline 1 & Distilled water & Tube 1,2 and 3 & $1,2,3,4,5$ & $1.47,2.94,4.41,5.88,7.35$ \\
2 & CMC-0.5\% & Tube 1,2 and 3 & $1,2,3,4,5$ & $1.47,2.94,4.41,5.88,7.35$ \\
3 & CMC-1\% & Tube 1,2 and 3 & $1,2,3,4,5$ & $1.47,2.94,4.41,5.88,7.35$ \\
4 & Skim milk & Tube 1,2 and 3 & $1,2,3,4,5$ & $1.47,2.94,4.41,5.88,7.35$ \\
5 & Apple sauce & Tube 1,2 and 3 & $1,2,3,4,5$ & $1.47,2.94,4.41,5.88,7.35$ \\
6 & Tomato sauce & Tube 1,2 and 3 & $1,2,3,4,5$ & $1.47,2.94,4.41,5.88,7.35$ \\
\hline
\end{tabular}

Table 3. Thermophysical and rheological properties of fluids used in the simulation

\begin{tabular}{ccccccccc}
\hline \multicolumn{2}{c}{ Fluid name } & $\boldsymbol{\rho}\left(\mathbf{k g} / \mathbf{m}^{\mathbf{3}}\right)$ & $\boldsymbol{C}_{\boldsymbol{p}}(\mathbf{J} / \mathbf{k g K}) \boldsymbol{K}(\mathbf{W} / \mathbf{m K})$ & $\boldsymbol{\mu}\left(\right.$ Pa.s) $\boldsymbol{K}\left(\right.$ Pa.s $\left.\mathbf{s}^{\mathbf{n}}\right)$ & $\boldsymbol{n}$ & Reference \\
\hline Distilled water & 995.7 & 4178.4 & 0.604 & 0.001005 & - & - & \multirow{2}{*}{ Tuta } \\
CMC $(0.5 \%)$ & 997.6 & 4170.3 & 0.602 & - & 0.639 & 0.791 & $(2016)$ \\
CMC (1\%) & 999.5 & 4162.1 & 0.601 & - & 5.522 & 0.449 & \\
Skim milk & 1047.7 & 3943.7 & 0.5678 & 0.0059 & - & - & Romano \\
Apple sauce & 1104.9 & 3703.3 & 0.535 & - & 32.734 & 0.197 & $(2015)$ \\
Tomato sauce & 1036.9 & 4000 & 0.5774 & - & 3.9124 & 0.097 & \\
\hline
\end{tabular}


Here $\rho$ is the fluid density $\left(\mathrm{kg} / \mathrm{m}^{3}\right), C_{p}$ is specific heat $(\mathrm{kJ} / \mathrm{kgK}), T$ is the temperature $(\mathrm{K}), k$ is thermal conductivity $(\mathrm{W} / \mathrm{mK})$ and $Q(\mathrm{~kW})$ is heat energy respectively. On the left

The following four aspects have been used in presenting the results obtained as per the simulation cases conducted.

(a) Skin friction coefficient prediction:

Flow characteristics of the test fluids (Apple sauce, Tomato sauce, Skim milk, Distilled water, CMC-0.5\%, and CMC- $1 \%$ solutions) are determined by simulation in all the three helical tubes of different pitches at various flow rates i.e., 1, 2, 3, 4 and $5 \mathrm{~L} / \mathrm{min}$. The skin friction coefficient along the length of the helical tubes are to be plotted at various positions from inlet to outlet of the tubes i.e., 1(inlet), 2, 3, 4, 5, 6 and 7(outlet). The properties of the fluids to be used in the simulation are given in Table 3.

(b) Pressure drop calculations:

Pressure drop variations of the fluids at all the flow rates (1, 2, 3, 4 and $5 \mathrm{~L} / \mathrm{min})$ in all three tubes $(0.124 \mathrm{~m}, 0.062 \mathrm{~m}$ and $0.186 \mathrm{~m}$ pitch) are plotted across the tube ends i.e., inlet and outlet.

(c) Computation of velocity magnitude and molecular viscosity:

- Contours of velocity magnitude for all the test fluids at $3 \mathrm{~L} / \mathrm{min}$.

- Molecular viscosity contours of Apple sauce at all the flow rates $(1,2,3,4$ and $5 \mathrm{~L} / \mathrm{min})$ in all the three tubes of $0.124 \mathrm{~m}, 0.062 \mathrm{~m}$ and $0.186 \mathrm{~m}$ pitch.

(d) Heat energy required to attain $60^{\circ} \mathrm{C}$ at the outlet:

Keeping inlet and outlet temperatures constant i.e., $20^{\circ} \mathrm{C}$ and $60^{\circ} \mathrm{C}$, heat energies required by Apple sauce, Tomato sauce and Skim milk at all flow rates $(1,2,3,4$ and $5 \mathrm{~L} / \mathrm{min})$ in the helical tube of pitch $0.124 \mathrm{~m}$ are found.

\subsection{Mathematical modeling}

The present case undertaken involves the laminar singlephase flow of Newtonian and non-Newtonian fluids. The flow is steady and three-dimensional flow and heat transfer. Some of the basic practical assumptions are as follows.

a. Distilled water and Skim milk are considered as

Newtonian fluid under laminar conditions.

b. Apple sauce, Tomato sauce, CMC-0.5\%, and CMC$1 \%$ are considered as non-Newtonian fluids.

c. Physical properties of fluids are considered as constant with temperature.

d. No phase change is considered.

e. Fluids are incompressible.

f. Fluid flows are in steady state condition.

g. The effect of gravity is considered.

Considering all these, the governing equations involved (i.e., continuity, momentum and energy equations) are presented below [19].

Continuity equation.

$$
\frac{\partial(\rho u)}{\partial x}+\frac{\partial(\rho v)}{\partial y}+\frac{\partial(\rho w)}{\partial z}=0
$$

Here $u, v$ and $w$ are velocities in $X, Y$ and $Z$ directions respectively, $\mathrm{m} / \mathrm{s}$.

Energy conservation equation.

$$
\rho C_{p} \frac{\partial T}{\partial t}+\mathrm{V} \nabla T=\nabla k \nabla T+Q
$$

side of the equation, $\frac{\partial T}{\partial t}$ is the change of temperature with time. It is used for unsteady state flows. For steady state conditions, the value of $\frac{\partial T}{\partial t}$ is Zero.

Momentum conservation equation.

$$
\rho\left[\frac{\partial V}{\partial t}+(V . \nabla) V\right]=-\nabla P+\rho \vec{g}+\mu \nabla^{2} \vec{V}
$$

Here $\nabla P$ is the pressure gradient $(\mathrm{Pa} / \mathrm{m}), \mu$ is the dynamic viscosity of the fluid. In the left side, $\frac{\partial V}{\partial t}$ is the change of velocity with time and $(V . \nabla) V$ is the speed and direction in which the fluid is moving. On the right side of the equation, $\nabla P$ denotes that the fluid flows in the direction of the largest change in pressure. $\rho \vec{g}$ is the gravitational force i.e., the weight of the fluid $\mu \nabla^{2} \vec{V}$ is the internal stress force acting on the fluid (considering the viscous effects). For non-Newtonian fluids, viscosity operates as a diffusion term.

\section{COMPUTATIONAL METHODOLOGY}

\subsection{Computational domain and boundary conditions}

The geometry of full physical domain is considered as fluid in the helical tube. The diameter of the tube is $0.038 \mathrm{~m}$. The vertical rise (pitch) of the tube is $0.124 \mathrm{~m}$ per unit length. Curvature ratio of the helical coil (ratio of the inside diameter of the tube to the diameter of the coil, where the diameter of the coil is measured from tube-centerline to tube centerline) is 0.105 . The length of the tube inside the cavity is $1.54 \mathrm{~m}$. With these all dimensions, the helical tube is modeled in ANSYS Design Modeler. The computational mesh is generated with hexahedral elements having desired boundary conditions using ANSYS meshing. The different types of helical tube cases and mesh sizes used are given in the Table 4. Figure 2 and Figure 3 show the generated mesh consisting of hexahedral elements. The total number of mesh elements in the mesh is 130698 . The boundary conditions for the various cases are given in the Table 5. In Figure 4, positions 1 and 7 are the main inlet and main outlet of the tube. Position 2 and 6 are inlet and outlet of the helical tube. The surfaces from 2 to 6 are created by using coordinate planes (Table 6). In the Cartesian coordinate system, the origin is situated at the center of the surface 2 .

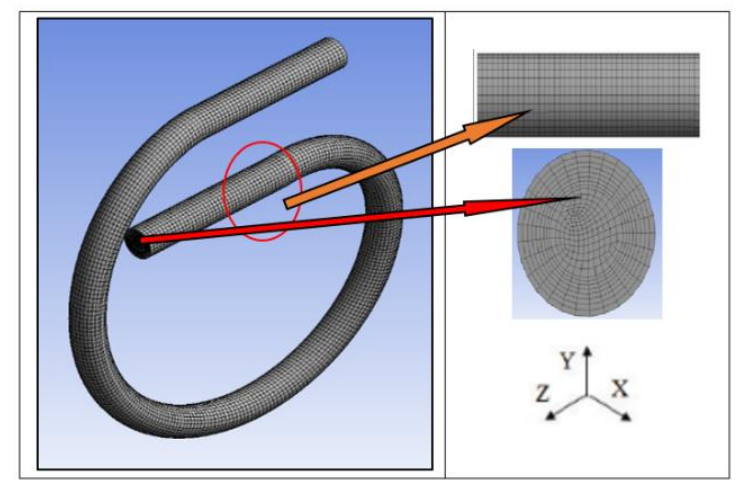

Figure 2. Structured mesh of helical tube with $0.124 \mathrm{~m}$ pitch 


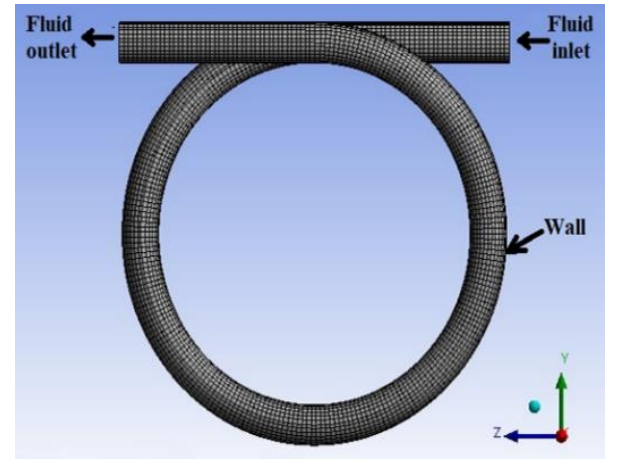

Figure 3. Top view of the computational mesh showing flow directions

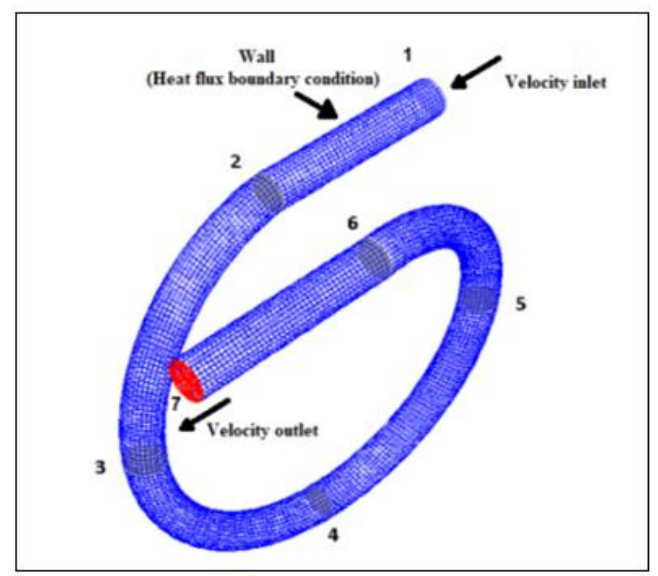

Figure 4. Positions of iso-surfaces 1-7 in the mesh

Table 4. Different helical tubes and Mesh size for validation given in Figure 5

\begin{tabular}{cccc}
\hline Helical Tube case & $\mathbf{1}$ & $\mathbf{2}$ & $\mathbf{3}$ \\
\hline Pitch length, $p(\mathrm{~m})$ & 0.124 & 0.062 & 0.186 \\
No. of mesh elements & 130698 & 129653 & 136196 \\
\hline
\end{tabular}

Table 5. Boundary conditions

\begin{tabular}{ccc}
\hline Boundary & For cases 1, 2 and 3 & For case 4 \\
Inlet & Velocity inlet and $20^{\circ} \mathrm{C}$ & Velocity inlet and \\
& temperature & $20{ }^{\circ} \mathrm{C}$ temperature \\
Wall & Stationary wall, no heat & Stationary wall, no \\
& flux & heat flux \\
Outlet & Pressure outlet & $\begin{array}{c}\text { Pressure outlet, } 60^{\circ} \mathrm{C} \\
\text { temperature }\end{array}$ \\
\hline
\end{tabular}

Table 6. Development of surfaces inside the helical tube

\begin{tabular}{ccccc}
\hline Surface & Base plane & clipped w.r.t & from & to \\
\hline 2 & $Z=0$ & $X$-axis & -0.019 & 0.019 \\
3 & $Y=-0.181$ & $Z$-axis & 0.16 & 0.198 \\
4 & $Z=0$ & $X$-axis & 0.043 & 0.081 \\
5 & $Y=-0.181$ & $Z$-axis & -0.198 & -0.16 \\
6 & $Z=0$ & $X$-axis & 0.105 & 0.143 \\
\hline
\end{tabular}

\subsection{Solution methodology}

Pressure based solver and finite volume methods are used as solver and numerical methods for the simulation. The laminar model is used as a viscous model. The solution methods and under-relaxation factors used are given in Table 7. The convergence criterion used in the simulation is $10^{-5}$. The solution methods and under-relaxation factors used in the simulation are given in Table 7.

Table 7. Solution methods and under relaxation factors

\begin{tabular}{|c|c|c|c|}
\hline \multicolumn{2}{|c|}{ Solution methods } & \multicolumn{2}{|c|}{$\begin{array}{c}\text { Under-relaxation } \\
\text { factors }\end{array}$} \\
\hline Scheme & SIMPLE & Pressure & 0.3 \\
\hline Gradient & $\begin{array}{c}\text { Least squares cell } \\
\text { based }\end{array}$ & Density & 1 \\
\hline Pressure & Second order & Body forces & 1 \\
\hline Momentum & Second order upwind & Momentum & 0.7 \\
\hline Energy & Second order upwind & Energy & 1 \\
\hline
\end{tabular}

\subsection{Validation}

The computational procedure has been validated with the experimental results of Tuta [14]. The average outlet temperatures at the tube end are used for the validation. The results are given in Table 8 and shown in Figure 5. This shows the maximum deviation of less than $1 \%$ in the simulation results as compared to Tuta [14] results.

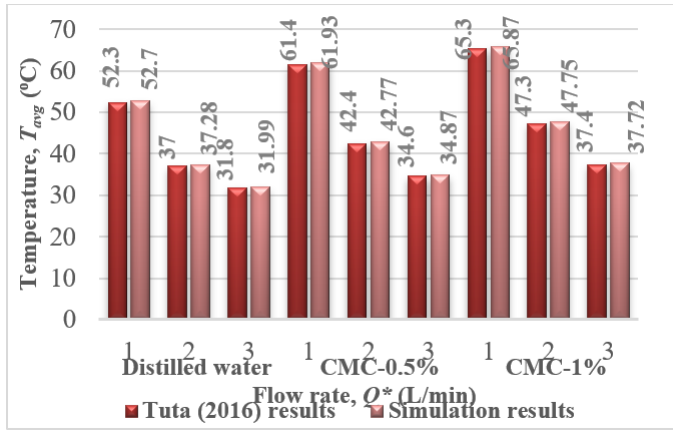

Figure 5. Comparison of simulation with Tuta, [14] results Validation

Table 8. Validation of simulation results with Tuta, [14] experiments

\begin{tabular}{ccccccc}
\hline $\begin{array}{c}\text { Fluid } \\
\text { name }\end{array}$ & $\begin{array}{c}\boldsymbol{Q}^{*} \\
(\mathbf{L} / \mathbf{m i n})\end{array}$ & $\begin{array}{c}\boldsymbol{Q} \\
(\mathbf{W})\end{array}$ & $\begin{array}{c}\boldsymbol{q} \\
\left(\mathbf{W} / \mathbf{m}^{2}\right)\end{array}$ & \multicolumn{2}{c}{$\boldsymbol{T}_{\boldsymbol{a v g}}\left({ }^{\circ} \mathbf{C}\right)$} & $\boldsymbol{T}$ \\
\hline \multirow{2}{*}{ Tistled $(\mathbf{2 0 1 6})$} & Simulation & Error \\
water & 1 & 2230.7 & 12133.53 & 52.3 & 52.7 & -0.77 \\
& 2 & 2355.2 & 12810.72 & 37 & 37.28 & -0.76 \\
& 3 & 2450 & 13326.37 & 31.8 & 31.99 & -0.60 \\
CMC & 1 & 2859.1 & 15551.60 & 61.4 & 61.93 & -0.86 \\
$(0.5 \%)$ & 2 & 3103.2 & 16879.34 & 42.4 & 42.77 & -0.87 \\
& 3 & 3037 & 16519.26 & 34.6 & 34.87 & -0.78 \\
CMC & 1 & 3128.2 & 17015.33 & 65.3 & 65.87 & -0.87 \\
$(1 \%)$ & 2 & 3781.8 & 20570.48 & 47.3 & 47.75 & -0.95 \\
& 3 & 619.2 & 19686.04 & 37.4 & 37.72 & -0.86 \\
\hline
\end{tabular}

\subsection{Mesh refinement study}

The different mesh sizes used for the mesh refinement study are given in Table 9. The following boundary conditions are chosen for mesh independent study.

- Apple sauce is selected as a fluid material.

- Fluid inlet velocity of $1 \mathrm{~L} / \mathrm{min}$ i.e., $0.0147 \mathrm{~m} / \mathrm{s}$ and $20^{\circ} \mathrm{C}$ temperature.

- The outlet boundary condition is kept as a pressure outlet with atmospheric pressure.

- Wall motion is kept stationary. No heat transfer is given to the wall. 
Table 9. Different mesh size for mesh refinement study

\begin{tabular}{cccccc}
\hline $\begin{array}{c}\text { Mesh } \\
\text { Number }\end{array}$ & $\mathbf{1}$ & $\mathbf{2}$ & $\mathbf{3}$ & $\mathbf{4}$ & $\mathbf{5}$ \\
\hline $\begin{array}{c}\text { Total } \\
\text { Elements }\end{array}$ & 109392 & 130698 & 170448 & 199068 & 255990 \\
$\begin{array}{c}\text { Peripheral } \\
\text { divisions }\end{array}$ & & & 30 & & \\
$\begin{array}{c}\text { Divisions } \\
\text { lengthwise }\end{array}$ & & & 318 & & \\
Radial layers & 6 & 8 & 15 & 18 & 25 \\
\hline
\end{tabular}

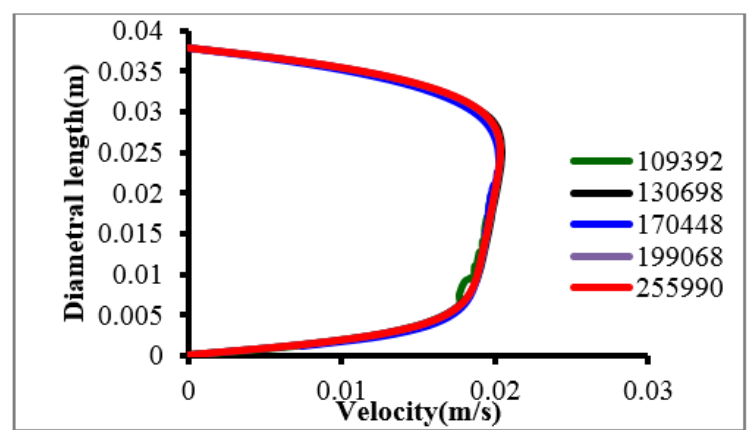

Figure 6. Velocity profiles for Apple sauce in different meshes - Mesh refinement study

A diametral iso-line with endpoints $A(0.062,-0.343,0)$ and $B(0.062,-0.381,0)$ is created on the surface 4 in (Figure 4$)$ inside the helical tube. Various velocity profiles of the line $A B$ are plotted by doing the simulation in various meshes with no. of elements which are shown below. Figure 6 shows that all the plots are nearly equal. All profiles of different mesh sizes are overlapping. The mesh size of 130698 elements is considered in the present study.

\section{RESULT AND DISCUSSION}

Apple sauce, Tomato sauce, Skim milk, Distilled water, CMC- $0.5 \%$, and CMC- $1 \%$ are used as fluid materials in computational modeling. These fluids are modeled at 1, 2, 3, 4 and $5 \mathrm{~L} / \mathrm{min}$ flow rates in helical tubes with $0.062 \mathrm{~m}, 0.124$ $\mathrm{m}$ and $0.186 \mathrm{~m}$ pitch lengths respectively. The finalized simulations have been presented in four aspects. In First aspect, the skin friction coefficient values for all the fluids at the mentioned flow rates are obtained and graphs are plotted. In second aspect, the pressure drop values for all the fluids across the helical tubes of $0.062 \mathrm{~m}, 0.124 \mathrm{~m}$ and $0.186 \mathrm{~m}$ pitches are obtained and compared graphically. In third aspect, the contours of velocity magnitude for the test fluids at $3 \mathrm{~L} / \mathrm{min}$ and molecular viscosity contours of Apple sauce at all the mentioned flow rates are shown. For all the three aspects, boundary conditions given are velocities (0.0147, 0.0294, $0.0441,0.0588$ and $0.0735 \mathrm{~m} / \mathrm{s}$ ) and $20^{\circ} \mathrm{C}$ temperature at the inlet of the helical tubes. No heat transfer is applied for the three cases. The viscous model used is the laminar model. In fourth aspect, assuming that the fluids need to attain $60{ }^{\circ} \mathrm{C}$ at the outlet of the tube the heat energies required by Apple sauce, Tomato sauce and Skim milk are obtained at all the flow rates in the helical tube of pitch $0.124 \mathrm{~m}$ and they are compared graphically. For this, boundary conditions applied are velocities $(0.0147,0.0294,0.0441,0.0588$ and $0.0735 \mathrm{~m} / \mathrm{s})$, $20^{\circ} \mathrm{C}$ temperature at inlet and $60^{\circ} \mathrm{C}$ temperature at outlet. All these are discussed as follows.

\subsection{Aspect 1: Variation of the skin friction coefficient $(f)$}

The graphs for skin friction coefficient values of Apple sauce are plotted in Figures 7(a)-7(c). Figure 7a shows that the skin friction coefficient is going on decreasing till position 4 and then it has got increased in between positions 4 and 5 up to the end of the helical tube (position 6). It is because of the high viscosity of the fluid and gravity. Figure $7 \mathrm{~b}$ shows that the skin friction coefficient is decreasing along the tube up to position 4 and again it is increasing in the remaining tube. By increasing the flow rate the skin friction coefficient of Apple sauce is decreasing due to its higher viscosity. Figure 7c shows that the skin friction coefficient for Apple sauce at $1 \mathrm{~L} / \mathrm{min}$ is 0.006 . At $2 \mathrm{~L} / \mathrm{min}$ the value is slightly decreased from 0.0069 to 0.0067 . At $3 \mathrm{~L} / \mathrm{min}$ the average value is 0.0073 . At $4 \mathrm{~L} / \mathrm{min}$ the value is decreasing from 0.0079 to 0.0076 inside the helical tube. And for $5 \mathrm{~L} / \mathrm{min}$ the average value is 0.008 .

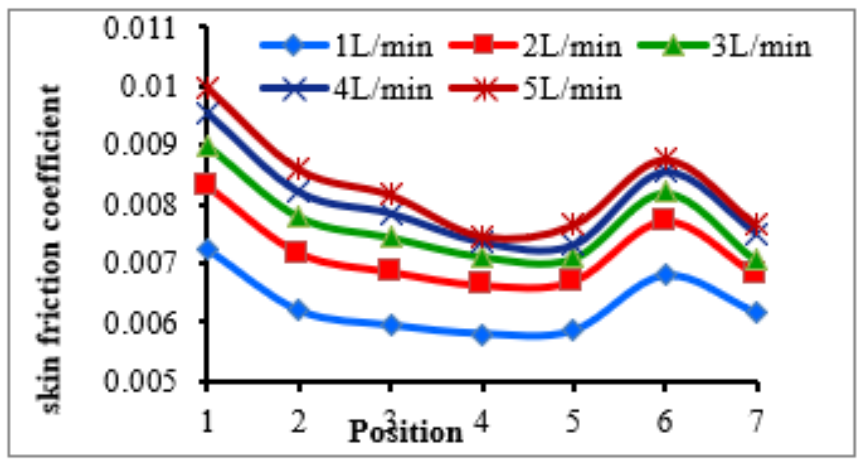

(a)

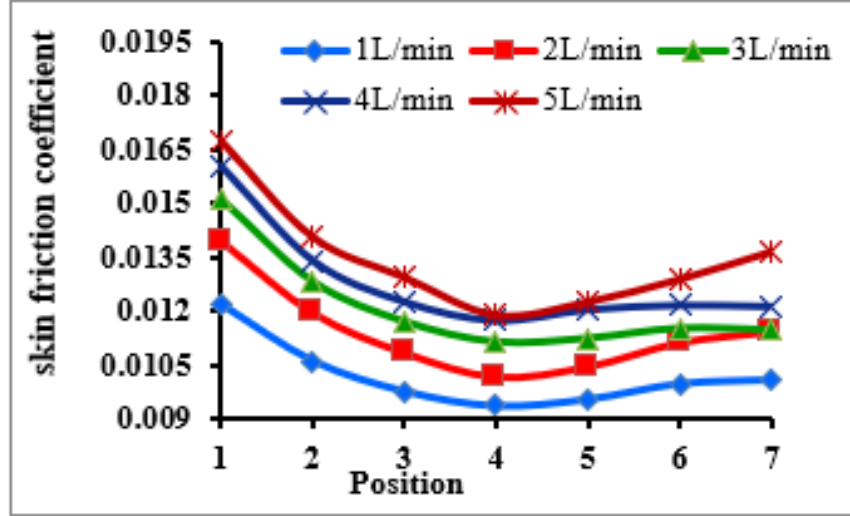

(b)

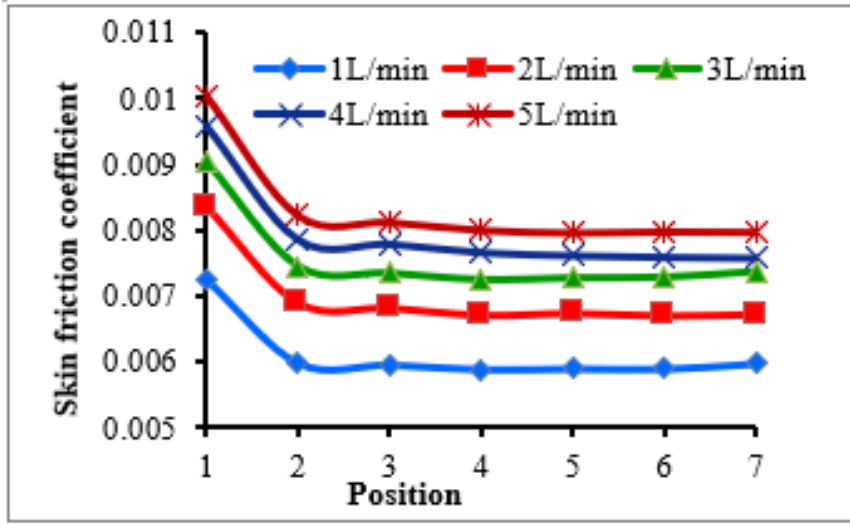

(c)

Figure 7. a) Skin friction coefficient along the tube of 0.062 $\mathrm{m}$ pitch for Apple sauce; b) Skin friction coefficient along the

tube of $0.124 \mathrm{~m}$ pitch for Apple sauce; c) Skin friction coefficient along the tube of $0.186 \mathrm{~m}$ pitch for Apple sauce 
The graphs for skin friction coefficient values of Tomato sauce are plotted in Figures 8(a)-8(c). Figure 8a shows that the skin friction coefficient is decreased up to position 4 and then it got increased from positions 4 to 5 because of higher viscosity of Tomato sauce. Figure $8 b$ shows that the skin friction coefficient is decreased along the tube up to position 4 and then increased in the remaining portion of the tube. It is due to the position of the tube and gravity force. Figure $8 \mathrm{c}$ shows that the value of the skin friction coefficient is decreasing in the helical tube along its length and slightly increasing at the outlet. The overall change in the values of the skin friction coefficient is having very small changes.

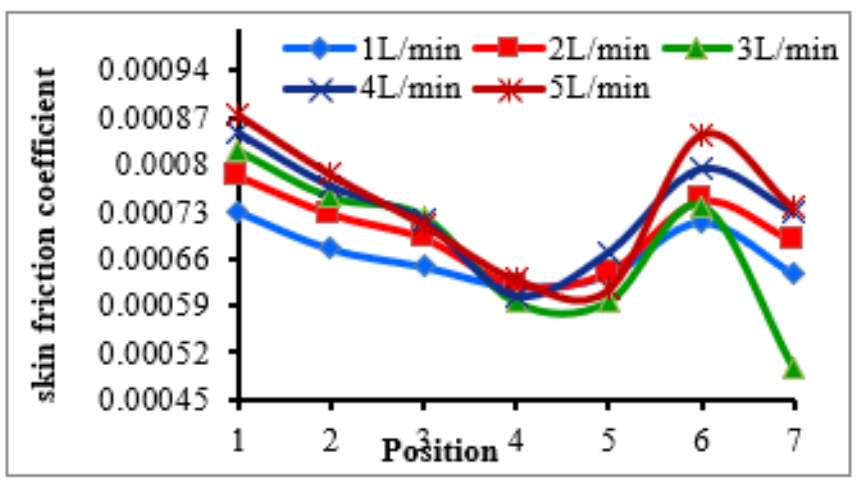

(a)

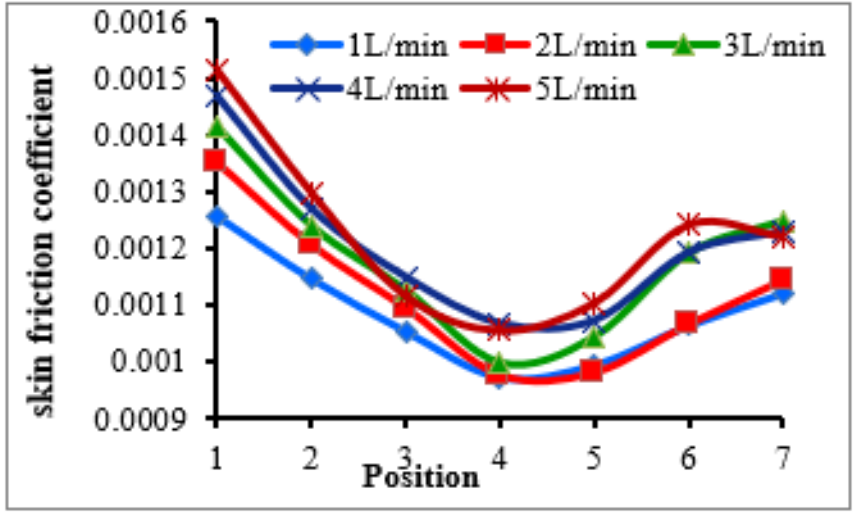

(b)

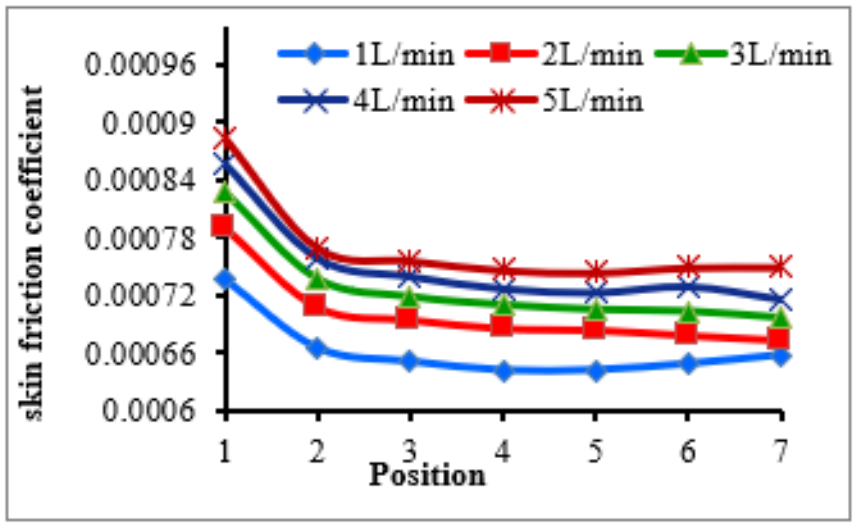

(c)

Figure 8. a) Skin friction coefficient along the tube of 0.062 $\mathrm{m}$ pitch for Tomato sauce; b) Skin friction coefficient along the tube of $0.124 \mathrm{~m}$ pitch for Tomato sauce; c) Skin friction coefficient along the tube of $0.186 \mathrm{~m}$ pitch for Tomato sauce

The graphs for skin friction coefficient values of CMC$0.5 \%$ are plotted in Figures 9(a) - 9(c). Figure 9a shows that the skin friction coefficient is increasing moderately along the length of the helical tube for all the flow rates. Figure $9 \mathrm{~b}$ shows that the skin friction coefficient at the entry of the helical tube i.e., position- 2 and then it is decreasing in the remaining tube. In Figure 9c the value of the skin friction coefficient is constant inside the helical tube almost for all the flow rates. Comparing with non-Newtonian fluids, the skin friction coefficient values are very less due to lower viscosity.

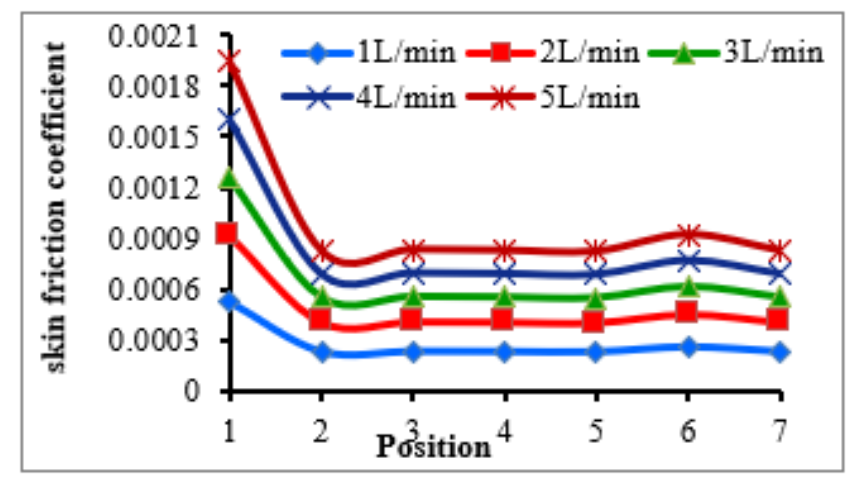

(a)

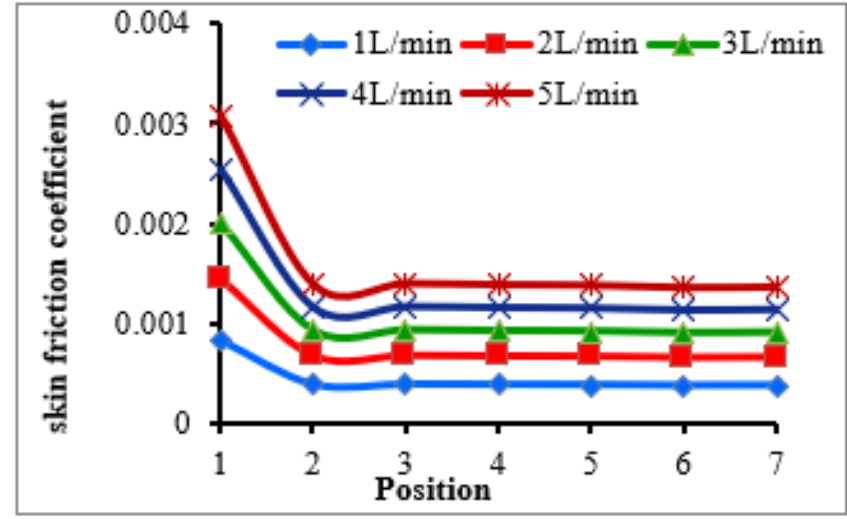

(b)

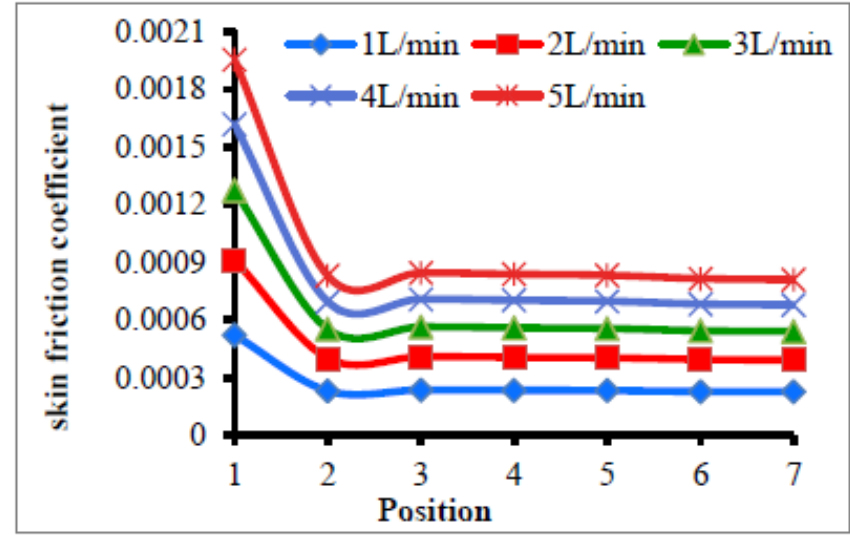

(c)

Figure 9. a) Skin friction coefficient along the tube of 0.062 $\mathrm{m}$ pitch for CMC- $0.5 \%$ solution; b) Skin friction coefficient along the tube of $0.124 \mathrm{~m}$ pitch for CMC- $0.5 \%$ solution; c) Skin friction coefficient along the tube of $0.186 \mathrm{~m}$ pitch for CMC- $0.5 \%$ solution

The graphs for skin friction coefficient values of CMC-1\% are plotted in Figures 10a-10c. Figure 10a shows that the skin friction coefficient is increasing moderately along the length of the helical tube for all the flow rates. Figure $10 \mathrm{~b}$ is showing that the skin friction coefficient is increased slightly from position 2 at all flow rates. Figure 10c shows that the skin friction coefficient for $\mathrm{CMC}-1 \%$ solution at all flow rates is constant inside the helical tube. 


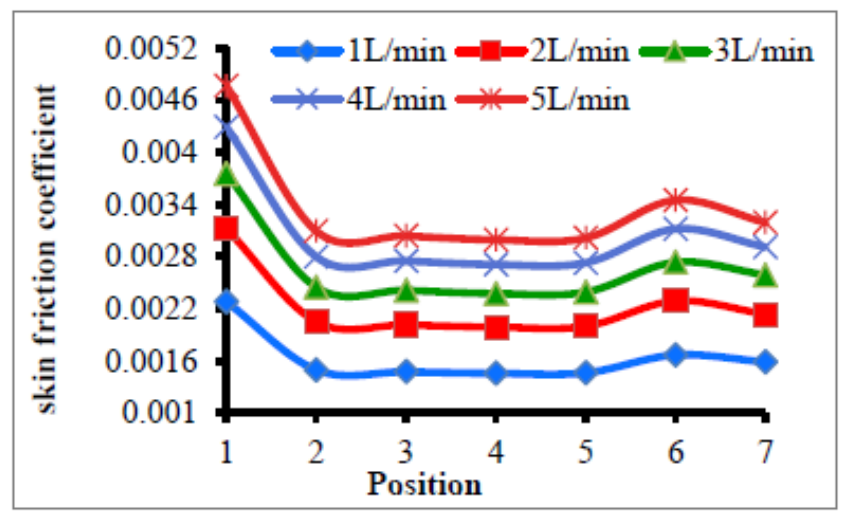

(a)

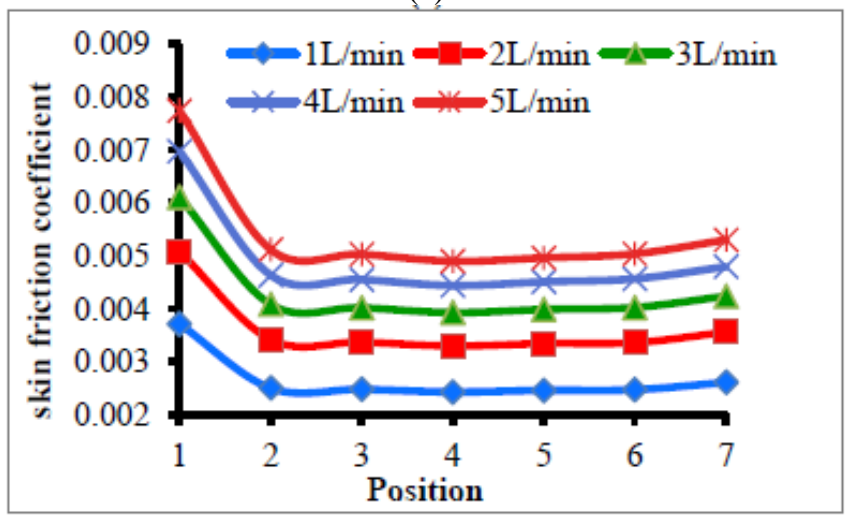

(b)

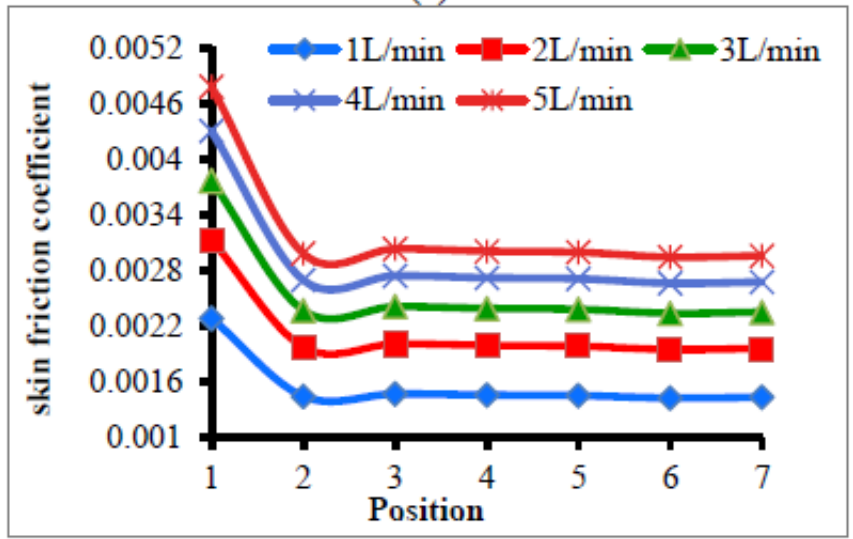

(c)

Figure 10. a) Skin friction coefficient along the tube of 0.062 $\mathrm{m}$ pitch for CMC-1\% solution; b) Skin friction coefficient along the tube of $0.124 \mathrm{~m}$ pitch for CMC- $1 \%$ solution; $\mathrm{c}$ ) Skin friction coefficient along the tube of $0.186 \mathrm{~m}$ pitch for CMC- $1 \%$ solution

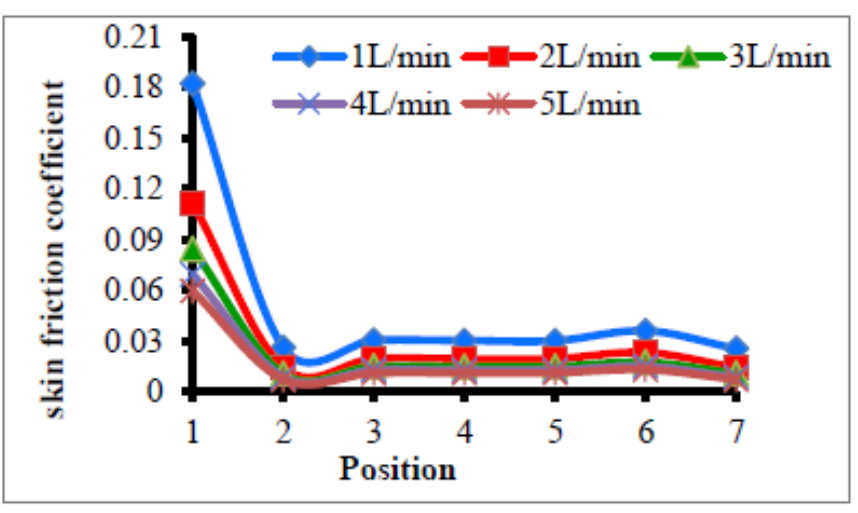

(a)

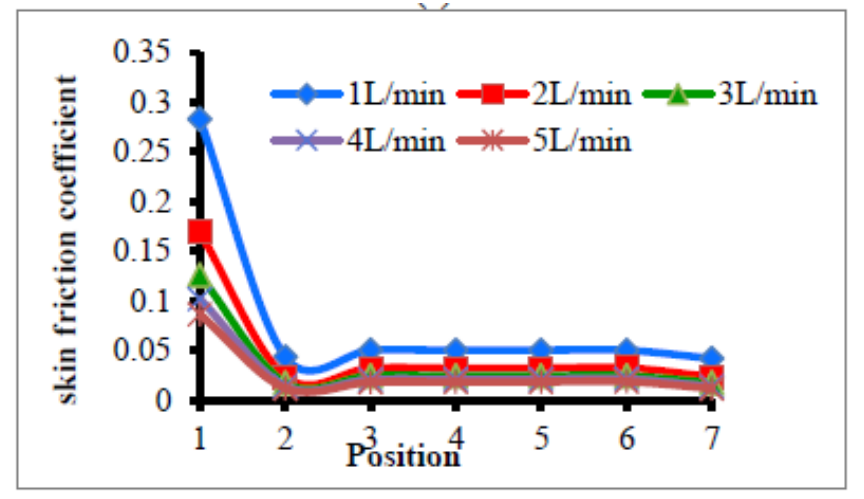

(b)

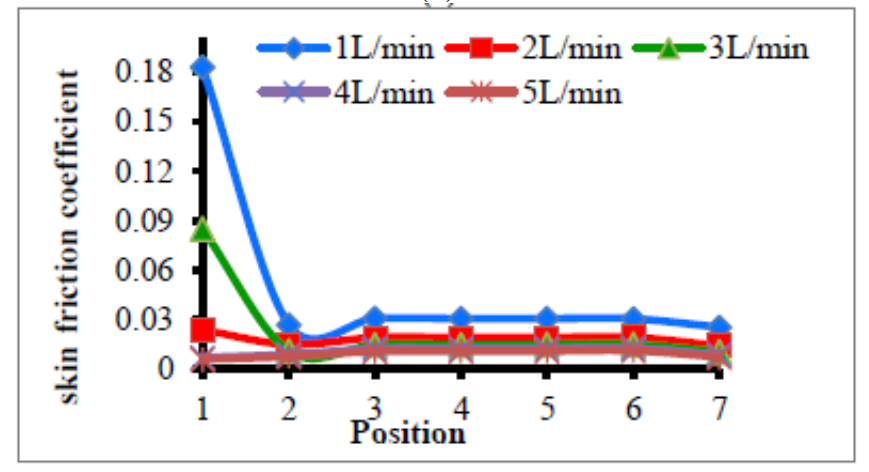

(c)

Figure 11. a) Skin friction coefficient along the tube of 0.062 $\mathrm{m}$ pitch for Skim milk; b) Skin friction coefficient along the tube of $0.124 \mathrm{~m}$ pitch for Skim milk; c) Skin friction coefficient along the tube of $0.186 \mathrm{~m}$ pitch for Skim milk

In Figure 11a, the skin friction coefficient for Skim milk is increasing slightly along the length of the helical tube for all the flow rates. Figure $11 \mathrm{~b}$ shows that the skin friction coefficient is slightly increased from position 1 to position 2 and then remained constant till the exit of helical tube i.e., position 6 . Figure $11 \mathrm{c}$ shows that skin friction coefficients for skim milk at 1 and $2 \mathrm{~L} / \mathrm{min}$ are increasing at the entrance of the tube and then decreasing slightly along the remaining tube. From 3 to $5 \mathrm{~L} / \mathrm{min}$ the values are increasing slightly along the tube.

Figure 12a shows that the skin friction coefficient Distilled water is increasing slightly along the length of the helical tube for all the flow rates. But as the flow rate is increased the value of the skin friction coefficient is getting decreased. Figure $12 \mathrm{~b}$ shows that there is a moderate increase in the skin friction coefficient from the inlet (position 2) of the helical tube to position 3 and then remained constant for the remaining length of the tube with very minute change. In Figure 12c, the value of the skin friction coefficient for distilled water is increasing moderately at the entrance of the helical tube and increasing slightly along the remaining tube from position 3 at all flow rates. As the flow rate is increased the value of the skin friction coefficient is decreasing.

\subsection{Aspect 2: The pressure drop computations $(\Delta \mathrm{P})$}

The graphs for pressure drop of Apple sauce, Tomato sauce, CMC-0.5\%, CMC-1\%, Skim milk, and Distilled water in all the tubes are plotted in the Figures 13-18. Figure 13 shows that the pressure drop across the tubes is increasing as the flow rate increases. At 2 and $3 \mathrm{~L} / \mathrm{min}$ flow rates, the pressure drop is minimum in the tube with $0.124 \mathrm{~m}$ pitch. For 4 and $5 \mathrm{~L} / \mathrm{min}$ 
flow rates, the pressure drop is almost the same in all tubes. Figure 14 shows that the pressure drop across the tube is minimum in the tube of pitch $0.124 \mathrm{~m}$ for all the flow rates. From 3 to $5 \mathrm{~L} / \mathrm{min}$ the pressure is almost the same in all tubes.

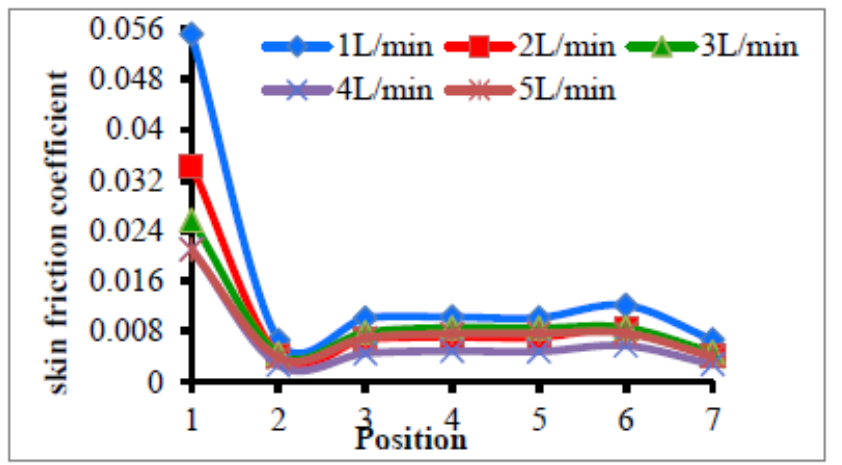

(a)

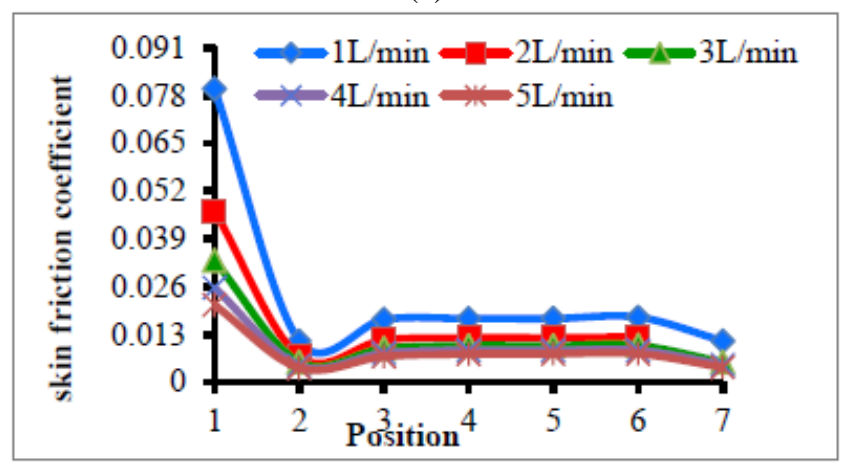

(b)

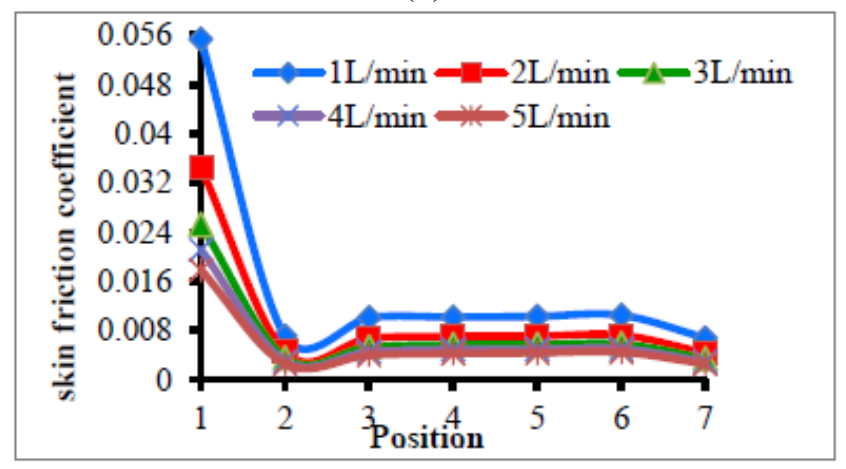

(c)

Figure 12. a) Skin friction coefficient along the tube of 0.062 $\mathrm{m}$ pitch for Distilled water; b) Skin friction coefficient along the tube of $0.124 \mathrm{~m}$ pitch for Distilled water; c) Skin friction coefficient along the tube of $0.186 \mathrm{~m}$ pitch for Distilled water

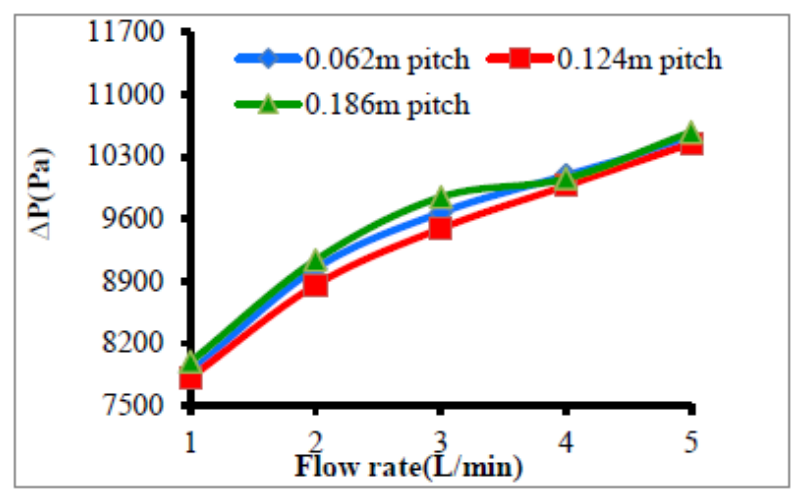

Figure 13. Pressure drop for apple sauce at various flow rates

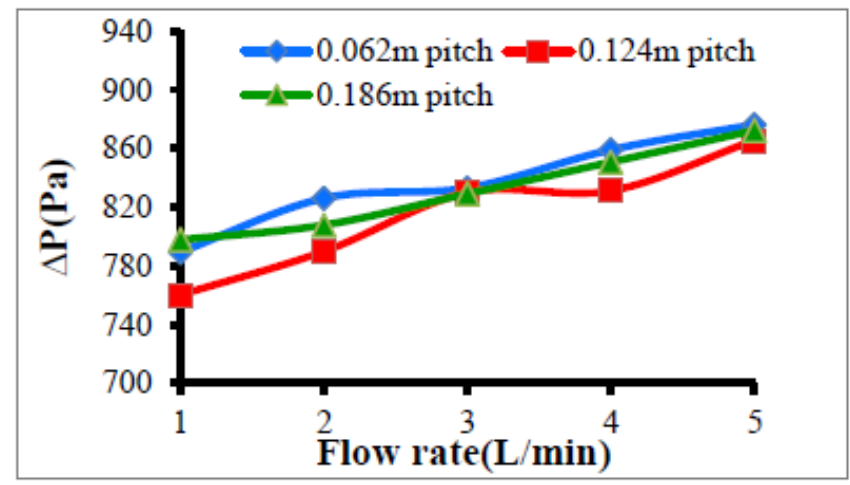

Figure 14. Pressure drop for tomato sauce at various flow rates

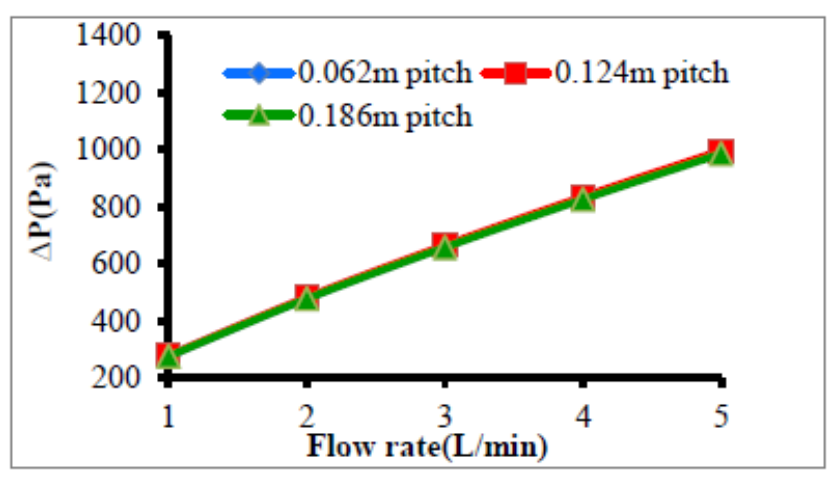

Figure 15. Pressure drop for CMC-0.5\% solution at various flow rates

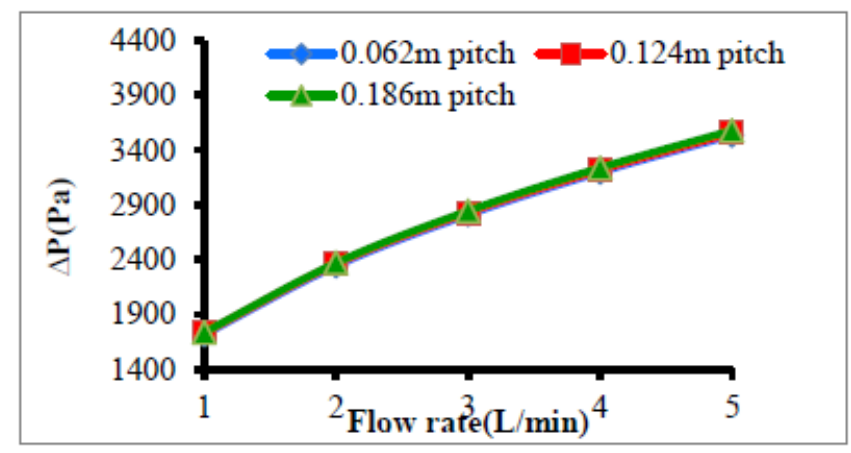

Figure 16. Pressure drop for $\mathrm{CMC}-1 \%$ solution at various flow rates

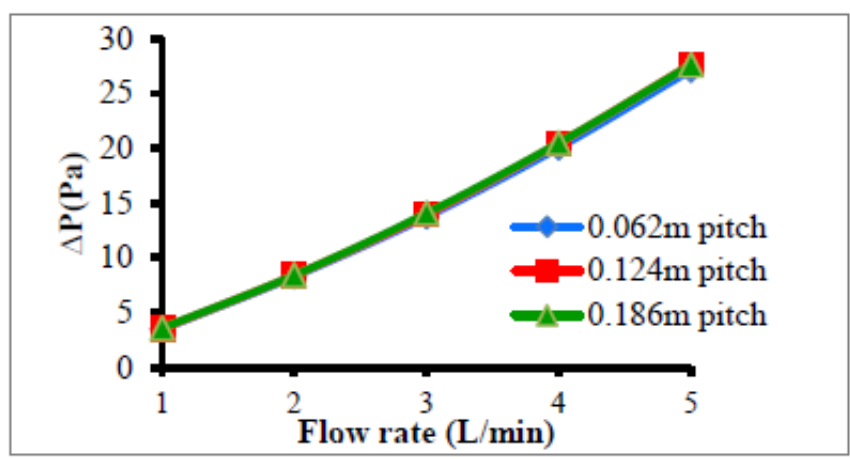

Figure 17. Pressure drop for skim milk at various flow rates

Figures 15, 16 and 17 show that the pressure drop is the same in all tubes at particular flow rates respectively. These results in that pressure drops are independent of the pitch 
length of the tubes. In Figure 18, the pressure drop is being the same at a particular flow rate in all tubes and this behavior is up to $3 \mathrm{~L} / \mathrm{min}$. From $4 \mathrm{~L} / \mathrm{min}$ flow rate there is a slight difference among the pressure drops in tubes of different pitches.

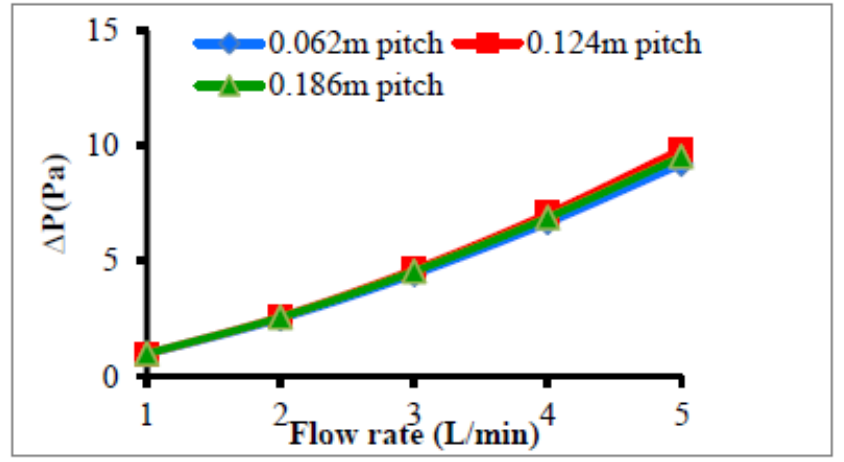

Figure 18. Pressure drop for distilled water at various flow rates

\subsection{Aspect 3: The contours of velocity and molecular viscosity}

Contours of the velocity magnitude of the test fluids at 3 $\mathrm{L} / \mathrm{min}$ and contours of molecular viscosity for Apple sauce at all 1,3 , and $5 \mathrm{~L} / \mathrm{min}$ flow rates are shown in Figures 19-25.

4.3.1 Contours of velocity magnitude for all test fluids at 3 $\mathrm{L} / \mathrm{min}$

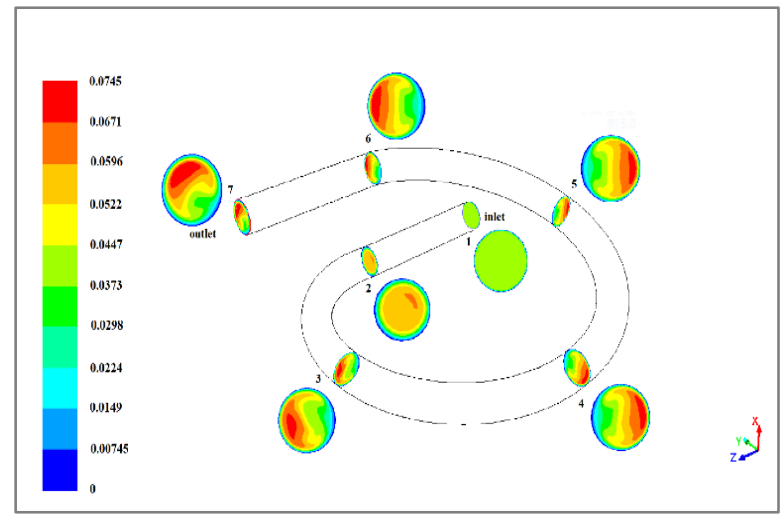

Figure 19. Contours of velocity magnitude $(\mathrm{m} / \mathrm{s})$ for Distilled water at $3 \mathrm{~L} / \mathrm{min}$

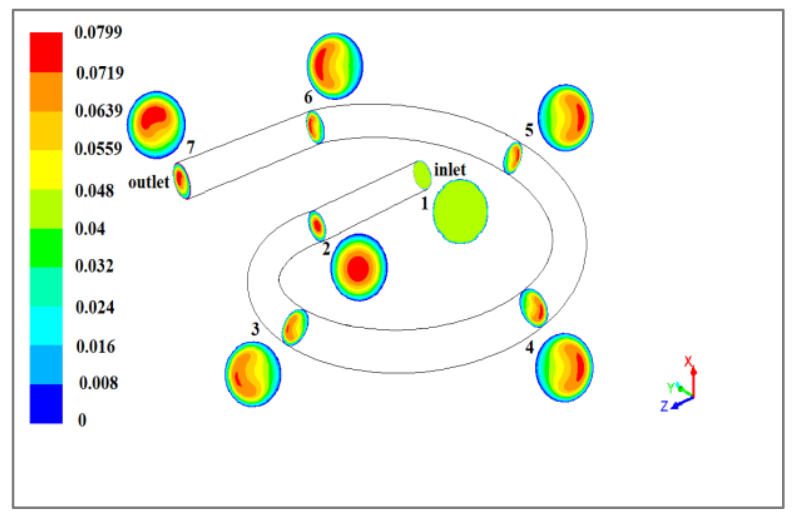

Figure 20. Contours of velocity magnitude $(\mathrm{m} / \mathrm{s})$ for Skim milk at $3 \mathrm{~L} / \mathrm{min}$

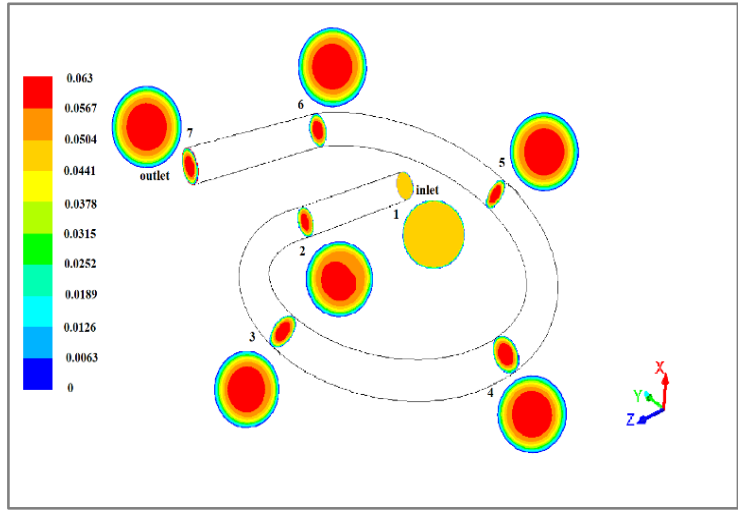

Figure 21. Contours of velocity magnitude (m/s) for Apple sauce at $3 \mathrm{~L} / \mathrm{min}$

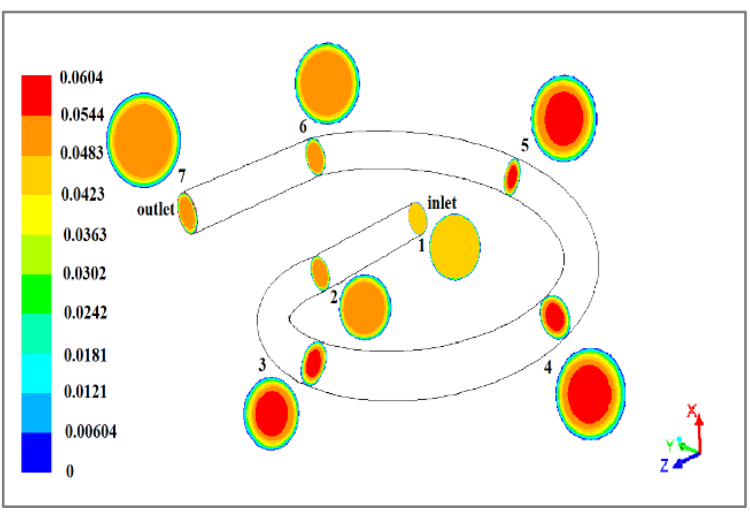

Figure 22. Contours of velocity magnitude $(\mathrm{m} / \mathrm{s})$ for Tomato sauce at $3 \mathrm{~L} / \mathrm{min}$

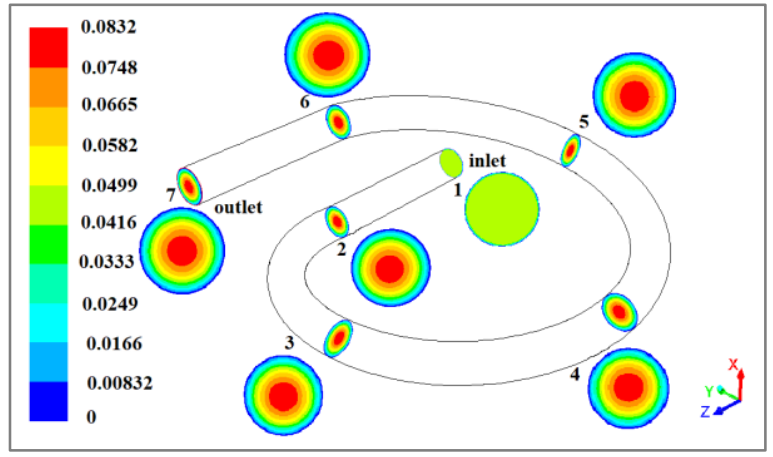

Figure 23. Contours of velocity magnitude $(\mathrm{m} / \mathrm{s})$ for CMC$0.5 \%$ at $3 \mathrm{~L} / \mathrm{min}$

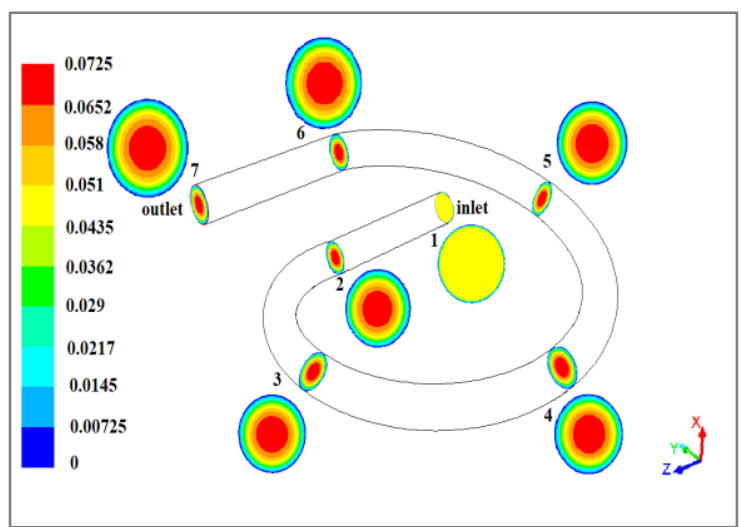

Figure 24. Contours of velocity magnitude $(\mathrm{m} / \mathrm{s})$ for CMC$1 \%$ at $3 \mathrm{~L} / \mathrm{min}$ 
As distilled water and skim milk are low viscous fluids the effect of tube curvature is more on their axial velocities. Therefore, the fluids are having higher axial velocities on the outer side and lower on the inner side of the tube.

Apple sauce and tomato sauce are highly viscous. So the effect of the curvature of the tube is very less on their axial velocities. Therefore, the axial velocity profiles for apple sauce are nearly uniform throughout the tube as it is due to the turntable effect of the tube. But the velocity profiles of tomato sauce are affected a little due to curvature of the tube as the effect can be seen at surfaces 3, 4 and 5 in Figure 22. In the case of $\mathrm{CMC}-0.5 \%$ and $\mathrm{CMC}-1 \%$ solutions, the velocity profiles shown in Figure 23 and 24 are uniform and the same for both the fluids due to having lower viscosities.

Velocity profiles for all the test fluids are drawn in Figure 25 on the line with endpoints A $(0.062,-0.343,0)$ and B $(0.062,-0.381,0)$ which is on position-4 surface inside the helical tube with $0.124 \mathrm{~m}$ pitch length.

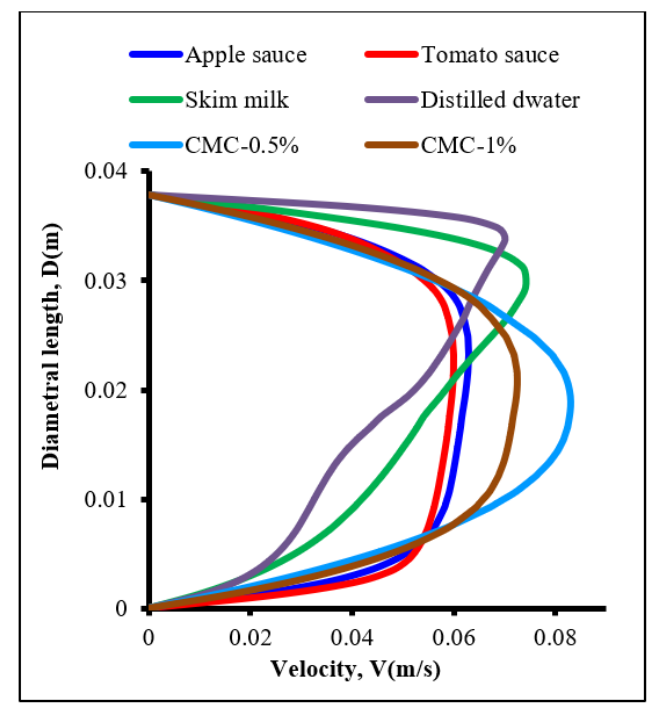

Figure 25. Velocity profiles of test fluids at $3 \mathrm{~L} / \mathrm{min}$ in the helical tube of $0.124 \mathrm{~m}$ pitch

4.3.2 Molecular viscosity $(\eta)$ contours of Apple sauce

Though contours of molecular viscosity (Figure 26) for Apple sauce at 1, 3 and $5 \mathrm{~L} / \mathrm{min}$ are as follow.

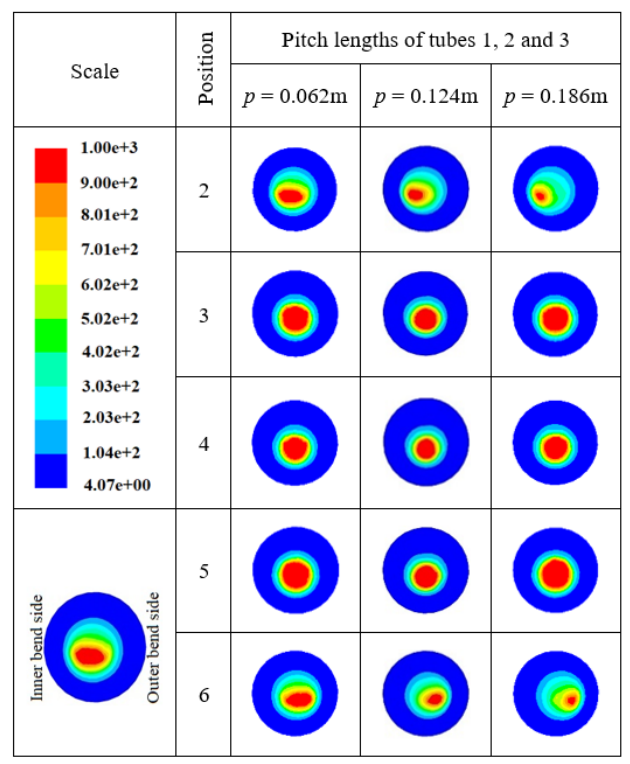

(a)

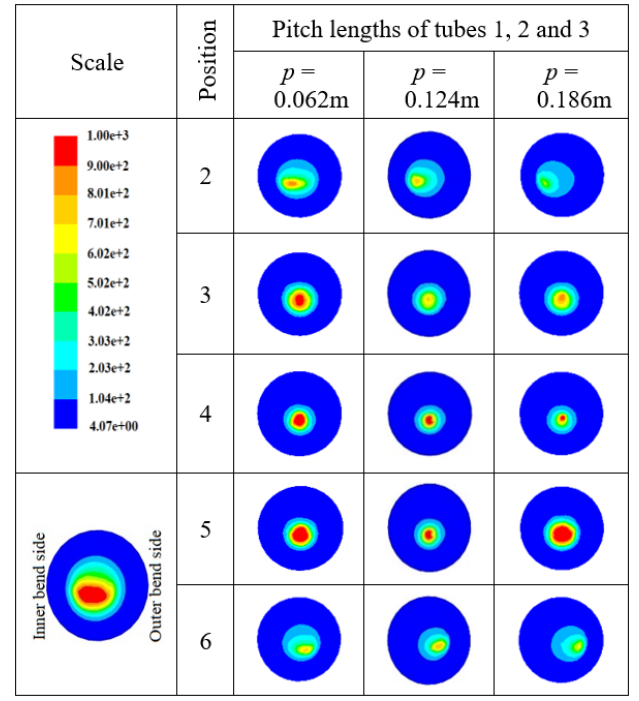

(b)

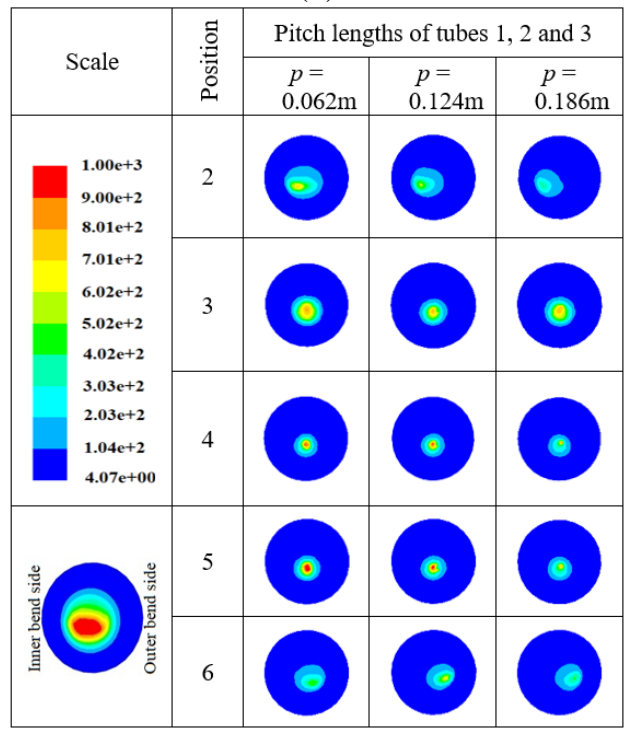

(c)

Figure 26. a) Contours of molecular viscosity ( $\mathrm{kg} / \mathrm{ms}$ ) for Apple sauce at $1 \mathrm{~L} / \mathrm{min}$; b) Contours of molecular viscosity $(\mathrm{kg} / \mathrm{m} . \mathrm{s})$ for Apple sauce at $3 \mathrm{~L} / \mathrm{min}$; c) Contours of molecular viscosity $(\mathrm{kg} / \mathrm{ms})$ for Apple sauce at $5 \mathrm{~L} / \mathrm{min}$

\subsection{Aspect 4: The heat energy required to attain $60^{\circ} \mathrm{C}$ at the outlet}

Assuming that Apple sauce, Tomato sauce and Skim milk need to attain $60^{\circ} \mathrm{C}$ at outlet, simulation has been performed to obtain heat energies required by the fluids at 1,2, 3, 4 and 5 $\mathrm{L} / \mathrm{min}$ flow rates. The helical tube used for this simulation is of $0.124 \mathrm{~m}$ pitch length. The viscous model used is the laminar model. Boundary conditions applied are velocity $(0.0147$, $0.0294,0.0441,0.0588$ and $0.0735 \mathrm{~m} / \mathrm{s}), 20^{\circ} \mathrm{C}$ temperature at inlet and $60^{\circ} \mathrm{C}$ temperature at outlet of the tube respectively. And these computational values of heat energy are compared with theoretical values of heat energies at the same boundary conditions.

Theoretically, heat energy required,

$$
q_{\text {th }}=m C_{p} \Delta T
$$

Here, mass flow rate,

$$
m=\rho a V
$$


Densities $(\rho)$ are of Apple sauce, Tomato sauce and Skim milk i.e., $1104.9,1036.9$ and $1047.4 \mathrm{~kg} / \mathrm{m}^{3}$ respectively. Tube cross sectional area, $\mathrm{a}=0.0011341 \mathrm{~m}^{2}$, Velocities, $V=0.0147$, $0.0294,0.0441,0.0588$ and $0.0735 \mathrm{~m} / \mathrm{s}$. Temperature difference, $\Delta T=60-20=40^{\circ} \mathrm{C}$.

Table 10. Comparison of computational and theoretical heat energy values

\begin{tabular}{ccccccc}
\hline $\begin{array}{c}\text { Fluid } \\
\text { name }\end{array}$ & $\begin{array}{c}\boldsymbol{Q} \\
(\mathbf{L} / \mathbf{m i n})\end{array}$ & $\begin{array}{c}\boldsymbol{V} \\
(\mathbf{m} / \mathbf{s})\end{array}$ & $\begin{array}{c}\boldsymbol{m} \\
(\mathbf{k g} / \mathbf{s})\end{array}$ & \multicolumn{2}{c}{$\boldsymbol{q}\left(\mathbf{k W} / \mathbf{m}^{\mathbf{2}}\right)$} & $\boldsymbol{q}$ \\
& 1 & 0.0147 & 0.0184 & 14.84 & 14.73 & 0.74 \\
Error \\
Apple & 2 & 0.0294 & 0.0173 & 29.68 & 29.45 & 0.77 \\
sauce & 3 & 0.0441 & 0.0175 & 44.53 & 44.18 & 0.79 \\
& 4 & 0.0588 & 0.0368 & 59.37 & 58.91 & 0.78 \\
& 5 & 0.0735 & 0.0346 & 74.21 & 73.64 & 0.77 \\
& 1 & 0.0147 & 0.0175 & 14.98 & 14.87 & 0.73 \\
Skim & 2 & 0.0294 & 0.0368 & 29.97 & 29.91 & 0.2 \\
milk & 3 & 0.0441 & 0.0346 & 44.95 & 46.17 & -2.71 \\
& 4 & 0.0588 & 0.0349 & 59.93 & 63.85 & -6.54 \\
& 5 & 0.0735 & 0.0553 & 74.91 & 79.39 & -5.98 \\
& 1 & 0.0147 & 0.0173 & 15.04 & 14.93 & 0.73 \\
Tomato & 2 & 0.0294 & 0.0175 & 30.09 & 29.85 & 0.8 \\
sauce & 3 & 0.0441 & 0.0368 & 45.13 & 44.78 & 0.78 \\
& 4 & 0.0588 & 0.0346 & 60.18 & 59.71 & 0.78 \\
& 5 & 0.0735 & 0.0349 & 75.22 & 74.64 & 0.77 \\
\hline
\end{tabular}

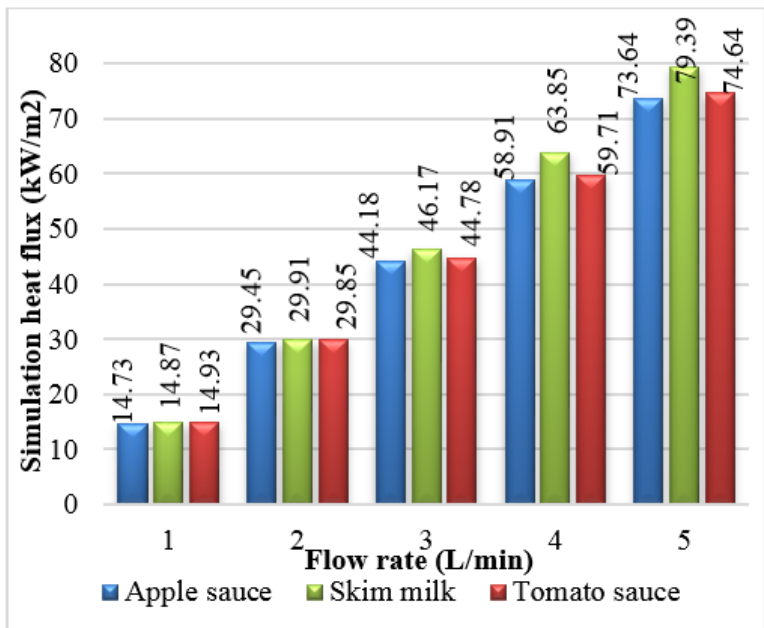

Figure 27. Heat energies required by Apple sauce, Tomato sauce, and Skim milk to attain $60^{\circ} \mathrm{C}$

The values of the computational heat energy are shown in Table 10. The column chart in Figure 27 shows that all three fluids need almost the same energy to attain $60^{\circ} \mathrm{C}$ at 1 and 2 $\mathrm{L} / \mathrm{min}$. From 3 to $5 \mathrm{~L} / \mathrm{min}$ Skim milk needs more amount of heat energy than that of Apple sauce and Tomato sauce.

\section{CONCLUSION}

In this study, an incompressible fluid domain through a helical tube in three-dimensional steady state was numerically modeled and simulated to understand the characteristics of flow and heat transfer through helical tubes of pitch lengths $0.124 \mathrm{~m}, 0.062 \mathrm{~m}$ and $0.186 \mathrm{~m}$ at flow rates $1,2,3,4$ and 5 $\mathrm{L} / \mathrm{min}$. The fluids used for the study are Apple sauce, Tomato sauce, Skim milk, Distilled water, CMC-0.5\%, and CMC- $1 \%$ solutions. The model was validated with experimental results of Tuta, [14]. Mesh refinement is studied. The viscous model used was the laminar model. For all the test fluids the increase in coil pitch decreased the skin friction coefficient. So, the coil pitch of the helical tube can be increased to reduce the friction factor until it won't affect the advantage of uniform heating in the tube. Pressure drop for Newtonian fluids is almost constant and is independent of pitch length of the tube whereas for nonNewtonian fluids pressure drop is dependent on pitch length of the tube. Contours of velocity magnitude of test fluids at 3 $\mathrm{L} / \mathrm{min}$ and contours of molecular viscosity of Apple sauce at 3 $\mathrm{L} / \mathrm{min}$ are presented. To attain $60{ }^{\circ} \mathrm{C}$ at the outlet of the tube, Skim milk needs more $4.5 \%$ of heat energy than that of Apple sauce and more $3.1 \%$ of heat energy than that of Tomato sauce at $3 \mathrm{~L} / \mathrm{min}$. At $4 \mathrm{~L} / \mathrm{min}$ Skim milk needs more $8.4 \%$ of heat energy than that of Apple sauce and more $6.9 \%$ of energy than that of Tomato sauce. Similarly, at $5 \mathrm{~L} / \mathrm{min}$ Skim milk needs more $7.8 \%$ of heat energy than that of Apple sauce and more $6.36 \%$ of energy than that of Tomato sauce. This numerical investigation may help for real time applications of designing helical tube inside the microwave cavity. Uniformity of heating food fluids can be further analyzed by increasing curvature ratio of helical tube and increasing turns of the tube. An increase in the length of the tube can increase the temperature during uniform heating. The computational modeling can also be performed for the unsteady state at higher flow rates i.e., turbulence models can be used.

\section{REFERENCES}

[1] Gentry, T.S., Roberts, J.S. (2005). Design and evaluation of a continuous flow microwave pasteurization system for apple cider. LWT - Food Science and Technology, 38(3): http://dx.doi.org/10.1016/j.lwt.2004.05.016 227-238.

[2] Nikdel, S., Chen, C.S., Parish, M.E., Mackellar, D.G., Friedrich, L.M. (1993). Pasteurization of citrus juice with microwave-energy in a continuous-flow unit. Journal of Agricultural and Food Chemistry, 41(11): 2116-2119. https://doi.org/10.1021/jf00035a055

[3] Coronel, P., Simunovic, J., Sandeep, K.P. (2003). Temperature profiles within milk after heating in a continuous-flow tubular microwave system operating at 915 MHz. Journal of Food Science, 68(6): 1976-1981. http://dx.doi.org/10.1111/j.1365-2621.2003.tb07004.x

[4] Sierra, I., Vidal-Valverde, C., Olano, A. (1999). The effects of continuous flow microwave treatment and conventional heating on the nutritional value of milk as shown by influence on vitamin B1 retention. European Food Research and Technology, 209: 352-354. https://doi.org/10.1007/s002170050508

[5] Valero, E., Villamiel, M., Sanz, J., Martinez-Castro, I. (2000). Chemical and sensorial changes in milk pasteurized by microwave and conventional systems during cold storage. Food Chemistry, 70(1): 77-81. https://doi.org/10.1016/S0308-8146(00)00074-1

[6] Villamiel, M., Lopez Fandino, R., Corzo, N., MartinezCastro, I., Olano, A. (1996). Effects of continuous flow microwave treatment on chemical and microbiological characteristics of milk. Zeitschrift für LebensmittelUntersuchung und Forschung, 202: 15-18. https://doi.org/10.1007/BF01229677

[7] Coronel, P., Truong, V., Simunovic, J., Sandeep, K.P., Cartwright, G.D. (2005). Aseptic processing of sweet potato purees using a continuous flow microwave system. 
Journal of Food Science, 70(9): 531-536. https://doi.org/10.1111/j.1365-2621.2005.tb08315.x

[8] Steed, L.E., Truong, V.D., Simunovic, J., Sandeep, K.P., Kumar, P., Cartwright, G.D., Swartzel, K.R. (2008). Continuous flow microwave-assisted processing and aseptic packaging of purple-fleshed sweet potato purees. Journal of Food Science, 73(9): 455-462. https://doi.org/10.1111/j.1750-3841.2008.00950.x

[9] Kumar, P., Coronel, P., Truong, V.D., Simunovic, J., Swartzel, K.R., Sandeep, K.P., Cartwright, G. (2008). Overcoming issues associated with the scale-up of a continuous flow microwave system for aseptic processing of vegetable purees. Food Research International, 41(5): 454-461. https://doi.org/10.1016/j.foodres.2007.11.004

[10] Thostenson, E.T., Chou, T.W. (1999). Microwave processing: fundamentals and applications. Composites Part A: Applied Science and Manufacturing, 30(9): 1055-1071. https://doi.org/10.1016/S1359$835 X(99) 00020-2$

[11] Zhu, J., Kuznetsov, A.V., Sandeep, K.P. (2007b). Mathematical modeling of continuous flow microwave heating of liquids (effects of dielectric properties and design parameters. International Journal of Thermal Sciences, 46(4): $328-341$ https://doi.org/10.1016/j.ijthermalsci.2006.06.005

[12] Salvi, D., Ortego, J., Arauz, C., Sabliov, C.M., Boldor, D. (2009). Experimental study of the effect of dielectric and physical properties on temperature distribution in fluids during continuous flow microwave heating. Journal of Food Engineering, 93(2): 149-157. http://dx.doi.org/10.1016/j.jfoodeng.2009.01.00

[13] Romano, V., Apicella, R. (2015). Microwave heating of liquid foods. Engineering, 7: 297-306. http://dx.doi.org/10.4236/eng.2015.76026

[14] Tuta, S., Palazoglu, T.K. (2016). Finite element modeling of continuous flow microwave heating of fluid foods and experimental validation. Journal of Food Engineering, 192:

$79-92$. https://doi.org/10.1016/j.jfoodeng.2016.08.003

[15] Tang, L., Tang, Y., Parameswaran, S. (2016). A numerical study of flow characteristics in a helical pipe. Advances in Mechanical Engineering, 8(7): 1-8. https://doi.org/10.1177/1687814016660242

[16] Adarsh, M., Kalla, Devaraju, R., (2017). Microwave energy and its application in food industry: A review. Asian Journal of Dairy and Food Research, 36(1): 37-44. http://dx.doi.org/10.18805/ajdfr.v0iOF.7303

[17] Deepali, J., Patrick, D.P. (2018). Computational evaluation of food carrier designs to improve heating uniformity in microwave assisted thermal pasteurization. Innovative Food Science \& Emerging Technologies, 48: 274-286. http://dx.doi.org/10.1016/j.ifset.2018.06.015

[18] Deepali, J., Yoon, K.H. (2019). Effect of changes in salt content and food thickness on electromagnetic heating of rice, mashed potatoes and peas in $915 \mathrm{MHz}$ single mode microwave cavity. Food Research International, 119: 584-595. https://doi.org/10.1016/j.foodres.2018.10.036

[19] ANSYS Fluent Theory Guide, ANSYS, Inc., 275 Technology Drive Canonsburg, PA 15317, November 2013.

http://www.pmt.usp.br/academic/martoran/notasmodelo sgrad/ANSYS\%20Fluent\%20Theory\%20Guide\%2015. pdf.

\section{NOMENCLATURE}

$\begin{array}{ll}Q^{*} & \text { flow rate, } \mathrm{L} \cdot \mathrm{min}^{-1} \\ V & \text { velocity, } \mathrm{m} \cdot \mathrm{s}^{-1} \\ C_{P} & \text { specific heat, } \mathrm{J} \cdot \mathrm{kg}^{-1} \cdot \mathrm{K}^{-1} \\ k & \text { thermal conductivity, } \mathrm{W} \cdot \mathrm{m}^{-1} \cdot \mathrm{K}^{-1} \\ K & \text { Flow consistency index, } \mathrm{Pa} \cdot \mathrm{s}^{\mathrm{n}} \\ n & \text { flow behavior index } \\ Q & \text { heat energy absorbed by fluid, } \mathrm{kW} \\ P & \text { pressure, Pa } \\ q & \text { heat flux, } \mathrm{kW} \cdot \mathrm{m}^{-2} \\ T_{a v g} & \text { average temperature at outlet, }{ }^{\circ} \mathrm{C} \\ f & \text { skin friction coefficient } \\ m & \text { mass flow rate, kg. } \mathrm{s}^{-1} \\ g & \text { gravitational acceleration, } \mathrm{m} \cdot \mathrm{s}^{-2} \\ \Delta T & \text { Temperature difference between outlet and } \\ & \text { inlet, }{ }^{\circ} \mathrm{C}\end{array}$

\section{Greek symbols}

$\rho \quad$ density, $\mathrm{kg} \cdot \mathrm{m}^{-3}$

$\mu \quad$ dynamic viscosity, Pa.s

$\eta \quad$ molecular viscosity, $\mathrm{m}^{2} \cdot \mathrm{s}^{-1}$

$\Delta \quad$ delta

\section{Subscripts}

$\begin{array}{ll}L & \text { length } \\ r & \text { remaining } \\ S & \text { straight tube } \\ P & \text { constant pressure }\end{array}$

